\section{DESASTRE MIGRATORIO EN EL TRÁNSITO MÉXICO-ESTADOS UNIDOS: CONTROL DE LA MIGRACIÓN, RACISMO Y COVID-19}

Nancy Rios-Contreras ${ }^{1^{*}}$

\section{RESUMEN}

Este artículo propone el uso de una perspectiva de desastre para una exploración teórica y ensayística sobre la migración en tránsito desde México hacia los Estados Unidos y que analiza el fenómeno más allá de una crisis migratoria o una amenaza de seguridad nacional. La reflexión teórica se basa en una investigación etnográfica centrada en el análisis de relatos periodísticos y observaciones presenciales y virtuales realizadas entre 2018 y 2020 en la frontera México-Estados Unidos. Las y los migrantes en tránsito enfrentan un 'desastre migratorio' con factores subyacentes como son la militarización, la securitización y la externalización de las fronteras. Además, legados históricos de racismo y anti-negritud y el contexto contemporáneo de la pandemia de COVID-19, son factores que refuerzan los impactos de manera concurrente y simultáneamente con el control migratorio. Durante la pandemia de COVID-19, las y los migrantes continúan siendo racializados y son afectados de manera desproporcionada. La planificación y la mitigación de desastres brinda alternativas para repensar posibles acciones que disminuyan el impacto del COVID-19 entre los migrantes latinoamericanos, ofreciendo un enfoque humanitario que aborde la desigualdad y el régimen de control migratorio.

\section{PALABRAS CLAVES}

Migración, COVID-19, Racismo, Desastres, Fronteras, México, Estados Unidos

\section{MIGRATORY DISASTER IN MEXICO-UNITED STATES TRANSIT: MIGRATION CONTROL, RACISM AND COVID-19}

\section{ABSTRACT}

This article proposes the use of a disaster perspective to explore transit migration from Mexico to the United States and to take the dialogue beyond a crisis and a national security threat. The theoretical reflection is based on ethnographic research focused on the analysis of journalistic stories and face-to-face and virtual observations made between 2018 and 2020 on the Mexico-United States border. Migrants in transit face a migration disaster with underlying factors such as militarization, securitization, and the externalization of borders. Likewise, historical legacies of racism and antiblackness, and the contemporary context of the COVID-19 pandemic, are concurrent factors that reinforce the migratory disaster and occur simultaneously with immigration enforcement. During the COVID-19 pandemic, migrants continue to be racialized and disproportionately affected. Disaster planning and mitigation provides alternatives to rethink possible actions that reduce the impact of COVID-19 on Latin American migrants by offering a humanitarian approach that addresses inequality and challenge the immigration control regime.

\section{KEYWORDS}

Migration, COVID-19, Racism, Disasters, Borders, Mexico, United States
1. Department of Sociology

and Criminal Justice,

University of Delaware,

Newark DE, Estados Unidos.

*Autor de correspondencia: rioscontreras@chapman.edu

Identificador:

http://revistareder.com/

handle-0719-8477-2020-o81

\section{RECIBIDO}

5 de noviembre de 2020

ACEPTADO

8 de diciembre de 2020

\section{PUBLICADO}

1 de julio de 2021

Formato cita

Recomendada (APA):

Rios-Contreras, N. (2021). Desastre Migratorio en el

Tránsito México-Estados

Unidos: Control de la

Migración, Racismo y

Covid-19. Revista de Estudios

Latinoamericanos sobre

Reducción del Riesgo de

Desastres REDER, 5(2), 168-

181. http://revistareder.com/ handle-0719-8477-2020-081

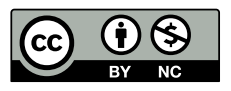

Todos los artículos publicados en REDER siguen una política de Acceso

Abierto y se respaldan en una Licencia CreativeCommons Atribución-NoComercial 4.0 Internacional.

Revista de Estudios Latinoamericanos sobre Reducción del Riesgo de Desastres (REDER)

Diseño: Lupe Bezzina 


\section{INTRODUCCIÓN}

Las investigaciones de la migración como un fenómeno social han documentado las relaciones entre México y Estados Unidos desde múltiples perspectivas durante la presidencia de Trump. El gobierno de Estados Unidos tiene una inversión económica especializada para el uso del control migratorio. La administración republicana de Trump aprobó un presupuesto en el 2020 que proporciona $\$ 18.2$ billones (dólares estadounidenses) para la Agencia Federal de Aduanas y Protección Fronteriza y $\$ 8.8$ billones para el Servicio de Inmigración y Control de Aduanas, mientras que el presupuesto federal para los gastos de salud se recorta constantemente cada año, incluso durante la pandemia del COVID-19. Además de comprender la complejidad de esta enfermedad, existe una gran necesidad de comprender el control migratorio de migrantes racializados. El control fronterizo de Estados Unidos y las restricciones a la movilidad utilizan discursos de salud pública y de los riesgos de una pandemia global para cerrar fronteras y oportunidades de migrar. El 20 de marzo del 2020, Estados Unidos anunció el cierre de la frontera con México para viajes no esenciales usando el Título 42 del Código Penal de Estados Unidos para la protección de la salud y el bienestar público. A medida que las preocupaciones sobre COVID-19 alcanzaban proporciones globales, las acciones federales demostraban que el enfoque de la administración Trump era el control de la migración mientras el contagio de la pandemia aumenta. Con esto, el objetivo de este estudio es captar sociológicamente el impacto de la pandemia en la vida de migrantes y con ello humanizar su experiencia como un acto político en un desastre migratorio más allá de una estadística o de un caso presuntamente positivo de COVID-19.

La disciplina de desastres que estudia desde las causas físicas de terremotos, huracanes, inundaciones, entre otros, hasta los impactos sociales, económicos y culturales de los desastres, pasando por las adaptaciones comunitarias a esos eventos, pueden proporcionar métodos alternativos para analizar el fenómeno de la migración en tránsito. Los desastres son creados por la convergencia de peligros provocados y una población que es física y/o socialmente vulnerable como son percibidas las comunidades de bajos ingresos y/o las comunidades negras y racializadas (Jacobs, 2019). Los desastres tienen mayor impacto en comunidades con mas vulnerabilidad. La relación entre la desigualdad racial y el desastre migratorio sigue siendo poco estudiada (Henricks, 2015). El control migratorio es ejemplo de un sistema que perpetúa la desigualdad racial. Usando la palabra 'desastre' en el contexto de la pandemia puede ayudar a dialogar sobre la gravedad del fenómeno, las consecuencias y posibles estrategias (Farías, 2020). La pandemia del COVID-19 no es solo una crisis de salud pública. La pandemia del COVID-19 revela desigualdades que están institucionalizadas en la sociedad y que probablemente seguirán existiendo después de que se controle la pandemia (Allen et al., 2020).

Desde una perspectiva de desastre migratorio, existen oportunidades para explorar la intersección del régimen del control migratorio, el racismo, y la pandemia del COVID-19. La frase 'Crisis Migratoria' se utiliza para describir los conflictos autorizados por el Estado para controlar la migración y el impacto perjudicial en la vida de las y los migrantes en tránsito. La palabra 'crisis' sugiere un evento que tendrá un cambio. Un paciente puede tener una crisis de comportamiento y con tratamiento y terapia mental puede encontrar un balance. Un desastre es un peligro para individuos que viven en condiciones de vulnerabilidad. Los desastres tienen consecuencias que impactan de manera desproporcional a individuos y comunidades marginalizadas en una jerarquía social. De esta forma, los desastres tienen manifestaciones de crisis, y desde esta perspectiva, el control migratorio es un desastre migratorio y social que puede manifestarse en crisis, pero usa prácticas de muerte para sostener las fronteras como espacios de segregación racializada (Mbembe, 2019).

Este artículo propone reflexiones teóricas centradas en el análisis de relatos periodísticos e interpretaciones que son producto de observaciones etnográficas -en formato presencial en el tiempo de campo y virtual- desde el 2018 en la frontera México-Estados Unidos. La erupción del COVID-19 provoca un desafío metodológico para investigadores que utilizan perspectivas cualitativas, en especial cuando existe la posibilidad de poner a migrantes en tránsito en riesgo de contagio. La metodología "de emergencia" utilizada intenta mitigar los efectos que perjudican los derechos humanos o la justicia social, como lo exacerba el contagio del virus (Cruz, 2017, p.209).

En este contexto, este trabajo y los métodos de investigación empleados siguieron las recomendaciones de salud pública: distancia social y reconocer la vulnerabilidad y la protección de 
migrantes viviendo en condiciones de precariedad. Con ello, la recolección de datos periodísticos y observaciones de campo y a distancia captaron el fenómeno de la migración y las experiencias de migrantes en tránsito durante la pandemia. Posteriormente, los datos fueron organizados en categorías y temas de análisis usando el programa NVivo. A modo de aprendizaje, se puede afirmar que la adaptación de herramientas metodológicas requiere extensiva planificación antes de entrar en una zona afectada por un desastre para minimizar el posible daño a migrantes y a investigadores, mientras se realiza el estudio de manera ética (Rios-Contreras, 2020).

\section{DESASTRE MIGRATORIO}

Para empezar a entender los desastres, sociales o socio-naturales, la clave es aceptar que los desastres no son naturales como muchas veces se menciona. No existen 'desastres naturales' debido a que personas e instituciones con intereses políticos y económicos se encargan de tomar las decisiones que las instituciones implementan y por lo tanto, resultan en desigualdad social (Hartman y Squires, 2006). Los desastres migratorios tienen cualidades sociales porque son "catástrofes precipitadas política y socialmente [...] cuando las personas son atacadas debido a algún aspecto de sus identidades sociales y sufren opresión, y persecución, ya sea a manos del estado o a través de prácticas sociales institucionalizadas, como el racismo" (Miller \& Wang, 2018, p.40). Los desastres amplían la brecha de equidad racial y perpetúan una forma de segregación racial (Henricks, 2015). Las pérdidas de desastres que afectan desproporcionadamente a individuos que viven en condiciones más vulnerables resultan de procesos en el orden social (Tierney, 2019). En otras palabras, quienes son considerados de una categoría baja en el orden social resultarían más impactados por los desastres, en comparación con quienes se encuentran en una categoría más alta o privilegiada.

La vulnerabilidad causada por condiciones sociales explica la existencia de desigualdades en el riesgo que hacen "que algunas personas sean más propensas al desastre que otras y estas desigualdades son en gran medida una función de las relaciones de poder (clase, edad, género y etnicidad entre otros)" (Bankoff, 2006). De manera similar como las autopsias médicas, los desastres también requieren 'autopsias sociales' para investigar con profundidad los procesos que contribuyen a la producción de una muerte en el sentido social o físico y seguir con la capacidad de la protección de vida (Klinenberg, 2015). Desde esta perspectiva, tres fenómenos sociales que inciden en un desastre migratorio serían: el control migratorio, el racismo y la pandemia del COVID-19. Una autopsia social de estos tres fenómenos sociales puede proporcionar un mejor entendimiento para proteger la vida de las y los migrantes en tránsito.

\section{Migración forzada}

En un momento en que la protección de la salud es una prioridad debido a una pandemia global, las y los migrantes hacen el viaje por México hacia Estados Unidos. Un debate en la literatura se refiere al estudio de la migración como resultado de migrantes que buscan mejores condiciones económicas versus migrantes que huyen de la violencia -0 migración forzada- (García, 2006; París Pombo, 2017; Sandoval-García, 2017). Las remesas que se envían al país de origen cuando los inmigrantes envían dinero a sus familias son utilizadas como factor para apoyar el motivo económico, pero los 'trabajadores' son personas que siempre migran por condiciones forzadas, señala Sandoval-García (2017). Países como Honduras, El Salvador y Guatemala enfrentaron la intervención de Estados Unidos en forma de producción económica, el control del trabajo local, financiamiento de guerras civiles, y violencia (Acuña, 2015). El interés de las empresas estadounidenses e internacionales por trasladar sus instalaciones de fabricación a México y Centroamérica contribuye a la explotación laboral y la migración forzada a Estados Unidos. Los sacrificios que están haciendo las personas para migrar a través de México a Estados Unidos ya no se basan únicamente en el 'sueño americano' como motivador. La violencia económica es un factor entre otros que contribuye al deterioro de las comunidades, lo que contribuye a la migración forzada (Dubuisson, 2018; Oviedo et al., 2020). La migración forzada también es provocada por decisiones políticas de los gobiernos, resultando en la persecución y violencia política contra migrantes (París Pombo, 2017). Además, la literatura coincide en que la vulnerabilidad social de los migrantes tiene varias causas no solo económicas (Thomas et al., 2013). Al comprender cómo los diferentes aspectos del proceso de migración forzada afectan la decisión de migrar, será posible reducir el impacto negativo de los desastres en estos grupos.

Los principales medios de comunicación retrataban la administración presidencial de Trump como la fuente de sentimientos antiinmigrantes. La retórica política antiinmigrante influye en los 
posibles riesgos sociales para las y los migrantes derivados de la violencia política. Aún así, en realidad, la literatura migratoria sugiere que esta retórica y el uso de políticas dirigidas a las y los migrantes han existido antes de Trump durante la presidencia de Obama, llegando a deportar más de 400.000 personas desde el 2012 (Chishti et al., 2017). También se debe recordar que Estados Unidos tiene una historia de intervencionismo en América Latina que sigue impactando la migración. Los factores políticos influyen en los cambios en las rutas migratorias disponibles, lo que coloca a las y los migrantes en mayor riesgo y vulnerabilidad mientras intentan evitar ser detectados por la policía o el ejército. Así, las rutas de migración cambian constantemente para evitar la detección y la persecución institucional, pero tomar rutas alternativas tiene consecuencias negativas para los migrantes. A pesar de que las y los migrantes viven la materialización de la violencia estructural, esta violencia no es un impedimento para ellas y ellos, pero sí la convierte en una migración forzada.

\section{Control migratorio}

La violencia contra migrantes y el control migratorio de las fronteras pueden entenderse con factores subyacentes de un desastre migratorio y social. El control migratorio no tiene condiciones de crisis inesperada. Un régimen global de fronteras considera el control de la migración como un proceso y un problema de seguridad nacional, de ilegalidad y de desigualdad económica que organiza flujos migratorios para explotar la mano de obra migrante (Mezzadra, 2005). La legislación dirigida a las y los migrantes limita sus derechos bajo un control de poder estatal que los ilegaliza y convierte en personas 'desechables' para el Estado (De Genova \& Roy, 2020).

El desastre del control migratorio no está enfocado en cuáles grupos están migrando de manera formal o irregular porque el enfoque es la violencia autorizada y ejecutada por el Estado. El régimen de Trump y la política de su administración intensifican la externalización de las fronteras de Estados Unidos. Estados Unidos ha cerrado sus fronteras al trabajar en la construcción del muro, al usar métodos de vigilancia, y al incrementar la colaboración entre la Patrulla Fronteriza y la Guardia Nacional (Villafuerte Solís, 2020). Una gran parte de las campañas presidenciales de Trump y de su administración ha sido la construcción del muro. El muro está basado en la ideología de asegurar las fronteras para proteger a la nación. La 'securitización' de la frontera específicamente controla la migración para evitar que se convierta en una amenaza para la seguridad (Sandoval-García, 2017). Para limitar la movilidad, o lo que Trump llama 'invasión', la externalización de fronteras implementa proyectos militarizados. La militarización es una estrategia del Estado para excluir y normalizar la muerte en un proceso de 'necrociudadanía' (Díaz-Barriga \& Dorsey, 2020). Las redes de la Guardia Nacional en México son ejemplo de la militarización de las fronteras debido a que las Fuerzas Armadas se activan en zonas de combate. En noviembre del 2020 fueron las elecciones presidenciales de los Estados Unidos y aunque aún eran tiempos de pandemia, el espectáculo de construir el muro parecía seguir adelante (Garrett, 2020).

Un ejemplo de la brutalidad del sistema de control migratorio incluye el abuso y la victimización de mujeres, niños, solteros y familias que migran. De mayo a julio de 2018, Estados Unidos implementó la política de 'cero tolerancia' y las imágenes de niños en jaulas y de la separación de familias se volvieron virales. Cuando la administración de Trump terminó con la política de cero tolerancia, el trauma mental siguió porque la separación de niños de sus seres queridos continuó. De septiembre del 2018 a mayo del 2019, seis niños ${ }^{1}$-con sus sueños y futuro- perdieron la vida bajo la custodia migratoria de Estados Unidos (Hennessy-Fiske, 2019).

Aunque la política de cero tolerancia ya no está activa, las familias continúan siendo separadas. El régimen de control migratorio atrapa a las y los migrantes y minimiza casi por completo las posibilidades de que puedan entrar a Estados Unidos de modo formal y legal. Cuando las y los migrantes luchan por su vida al intentar cruzar irregularmente a los Estados Unidos son detenidos y los acusan de delito, lo que resulta en la separación de familias, en 'la hielera' o cárcel de detención (Garrett, 2020).

El liderazgo de las luchas por Black Lives Matter ('Las Vidas Negras Importan') y de \#SayHerName ('Di el nombre de Ella') revela la importancia de recordar y mencionar los nombres de individuos que el Estado ha tratado de invisibilizar. En el caso de Black Lives Matter se refiere a las mujeres trans negras, quienes en contextos migratorios son uno de los grupos más invisibilizados que transitan por México. Las estadísticas y reportes sobre las y los migrantes en tránsito mutilan socialmente la identidad interseccional de los migrantes. Por lo tanto, los convierten en números de

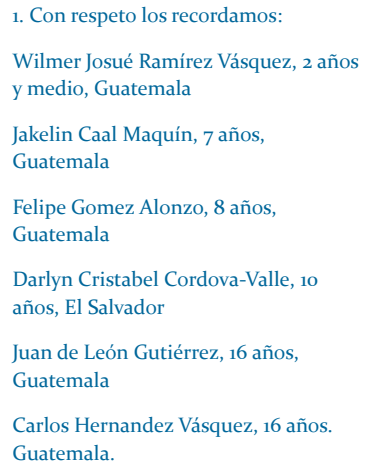


caso o en orden de lista de espera como lo son bajo la 'Política de Medición' ('Metering' en inglés). La violencia Estatal implementada por la Política de Medición hizo viral la imagen de un padre y una hija salvadoreños que murieron cruzando el Río Bravo el 24 de junio de 2019². El control de la migración no es sólo un proceso de separación familiar porque las políticas para controlar la movilidad humana están basadas en prácticas de muerte que siguen, por ejemplo, forzando a migrantes a cruzar la frontera en áreas clandestinas de alto riesgo.

La implementación de los Migrant Protection Protocols ('Protocolos de Protección al Migrante'), también conocido como la política de permanecer en México, tiene consecuencias catastróficas para las y los migrantes en tránsito. Esta política obliga a los solicitantes de asilo a esperar en una frontera que es militarizada por dos gobiernos y en zonas donde se encuentran en riesgo de victimización en ciudades fronterizas (Garrett, 2020). Antes de la pandemia del COVID-19, Estados Unidos estableció el Asylum Cooperation Agreement ('Acuerdo de Cooperación') con Guatemala y resultó en el traslado de guatemaltecos, hondureños y salvadoreños desde la frontera norte al sur (Garrett, 2020). Las políticas de la administración Trump y la participación del gobierno mexicano de López Obrador en conjunto sostienen un régimen de control migratorio y replican la externalización de fronteras porque México al mismo tiempo militariza la frontera con Guatemala.

\section{Racismo}

El racismo y la violencia contra humanos racializados a nivel estructural e interpersonal son también factores subyacentes del desastre migratorio. La creciente colaboración entre autoridades de migración y el sistema de justicia criminal, o más bien de injusticia, contribuye a la creación de un aparato carcelario que atrapa a migrantes irregulares y grupos racializados (Armenta, 2017). La patrulla fronteriza de los Estados Unidos también funciona bajo el ámbito de la desigualdad racial (Lytle Hernández, 2015). Las personas racializadas son sobrevivientes de la opresión histórica, prejuicios y discriminación. La esclavitud forzada contribuyó y aún sigue contribuyendo a la victimización de afrodescendientes. Existe el mito que en México no existe el racismo porque todos son parte del mestizaje, pero la "necropolítica de la desigualdad" reproduce la discriminación, marginalización, y la exclusión que se vive diariamente en México (Navarrete, 2016, p.171). Los centroamericanos no siempre son bienvenidos en México. Actualmente, la política étnica influye en la política migratoria porque el continente americano todavía no se encuentra en estado postétnico (Fitzgerald \& Cook-Martín, 2015). En México, los movimientos afro históricamente exigían reconocimiento étnico sin incluir a las mujeres, debido a que las relaciones de género no eran parte de la movilización. No obstante, un feminismo antiracista negro-afromexicano sigue en el proceso de construcción social (Varela Huerta, 2019).

El 25 de mayo de 2020 George Floyd fue asesinado por policias del departamento de Minneapolis en el estado de Minnesota y el mundo respondió con protestas que exigían justicia racial. Ciudadanos en Italia, Canadá, Francia, Japón y en muchos otros países también demostraron su apoyo al caso de la familia de George Floyd en contra del Departamento de Policía y a favor del movimiento Black Lives Matter. Las demostraciones después del linchamiento de Floyd en 2020 son parte del movimiento original y rejuvenecido, Black Lives Matter, de 2014, las cuales demuestran un pueblo que se subleva contra el racismo y la violencia del Estado. El 26 de febrero de 2012, un voluntario de vigilancia de un vecindario fue absuelto de todos los cargos por dispararle fatalmente a Trayvon Martin, un joven negro de 17 años en Florida, lo cual originó la creación del movimiento Black Lives Matter. Después, el 9 de agosto de 2014, un oficial de policía de Ferguson, Missouri, le disparó fatalmente a Michael Brown, un afroamericano de 18 años. Cuando la corte no lo juzgó, se hicieron protestas internacionalmente. En 2014, Black Lives Matter llamaba la atención hacia el abuso policial y al movimiento para que hubiera justicia para hombres y niños negros víctimas de violencia del Estado. Hubo un cambio en 2015 porque se difundió internacionalmente la muerte de una latina. El 26 de enero de 2015, policías de Denver, Colorado, le dispararon fatalmente a Jessica (Jessie) Hernández, una latina de 17 años, mientras que se encontraba en un vehículo en movimiento. Este caso se hizo viral a través de las redes sociales porque Jessie se identificaba como parte de la comunidad de LGBTQIA+. La interseccionalidad de su identidad expandió la imagen del abuso policial dirigido mayormente a la comunidad negra e iluminó la violencia policial contra Latino Americanos de diferentes orientaciones sexuales. Asimismo, el racismo se manifiesta en otras instituciones como en la educación, la segregación étnica residencial, el sistema de salud, y la política migratoria, entre otras.

2. Recordamos a Óscar Alberto Martínez Ramírez y su hija, Valeria, de un año de edad. 


\section{LOS ÉXODOS HUMANOS PARA CRUZAR FRONTERAS}

Un ejemplo del desastre migratorio incluye las migraciones como un éxodo humano, las cuales también son conocidas como caravanas en los medios de comunicación. Los informes sobre las migraciones masivas han aparecido en los titulares de los noticieros y los periódicos, de manera que la migración masiva en tránsito por México se ha documentado ampliamente. Desde 2005, caravanas anuales de madres centroamericanas migrantes organizadas por el 'Movimiento Migrante Mesoamericano', han transitado por México hasta la frontera entre Estados Unidos y México en busca de sus hijas desaparecidas en el tránsito migratorio (París Pombo \& Montes, 2020). En 2014, la migración de niños y jóvenes centroamericanos no acompañados consternaron al gobierno de Estados Unidos porque las y los migrantes eran menores de edad y las mujeres también emigraban con niños (Swanson \& Torres, 2019). Del 2016 a 2017, haitianos empezaron a llegar a Tijuana, México, con la motivación de solicitar una cita para aplicar al asilo en Estados Unidos (Dubuisson, 2018). Sin embargo, los procesos selectivos migratorios los dejaron atrapados en México (Alarcón Acosta \& Ortiz Esquivel, 2017; Silva Hernández \& Padilla Orozco, 2020). En 2017, el 'viacrucis migrante' de centroamericanos fue apoyado por la Iglesia Católica para protestar en contra de las injusticias contra las y los migrantes en México (París Pombo \& Montes, 2020). De octubre de 2018 hasta 2019, caravanas en curso desde Honduras, El Salvador y Guatemala hacia Estados Unidos también captaron la atención de la comunidad internacional y movilizaron a los académicos a reconsiderar los conceptos de la migración forzada, asilo, y la externalización de las fronteras. Los tránsitos de las migraciones masivas demuestran cómo las diferentes identidades de las y los migrantes son racializadas y enfrentan oposición del régimen de control migratorio y violencia del Estado sin importar si son niños, madres o familias. Las caravanas o el éxodo centroamericano alteraron el régimen del control migratorio porque la caravana funciona "como una rebelión [...] como un movimiento social de mujeres preservando la vida...como una insurgencia, [y] como una estrategia de autodefensa migrante" (Varela Huerta, 2020, pp.85-86).

\section{IMPACTOS Y FACTORES CONCURRENTES}

Cuando estudiamos la migración con una perspectiva teórica interdisciplinaria, se puede entender mejor cómo las y los migrantes (forzados o no) forman parte de un desastre migratorio, en donde múltiples aspectos sociales, económicos y políticos ocurren de manera concurrente, tanto en forma de factores subyacentes (causas) como de impacto (efectos), en su tránsito desde México hacia los Estados Unidos. Así, el impacto concurrente de un desastre migratorio ocurre simultáneamente con otros desastres, impactando la vida de individuos en condiciones de vulnerabilidad. El control migratorio, el racismo contra cuerpos racializados y el impacto desproporcionado del COVID-19 contribuyen al desastre migratorio, el cual ocurre frecuentemente junto a la movilización de la migración forzada. EI COVID-19 es una enfermedad con daños físicos, pero con impactos que van mucho más allá de lo biológico. El régimen del control migratorio 'entrampaba' a migrantes mucho antes de la pandemia con políticas anti-migrantes, un proceso que se podría entender también desde las 'trampas de riesgo' (Allen et al., 2017). Lo que es diferente durante la pandemia es que las políticas migratorias están gobernando la movilidad bajo el contexto de salud pública para cerrar fronteras a migrantes clasificados como no deseados o racializados.

Las y los migrantes en tránsito por México enfrentan impactos concurrentes mientras que enfrentan los requisitos que complican la migración formal y que han hecho la migración irregular aún más peligrosa. Los noticieros informan cómo México está subestimando drásticamente las muertes por COVID-19 (Friedman et al., 2020) al tiempo que las ciudades fronterizas como Tijuana ofrecen una perspectiva para entender la función de las fronteras durante un período de desastre migratorio. Por ejemplo, los casos reportados de COVID-19 en Tijuana estuvieron entre los primeros casos reportados en México (Friedman et al., 2020).

Prestar atención al desastre migratorio ayuda a que socialmente los grupos en situaciones de vulnerabilidad como las y los migrantes en tránsito no sean ignorados. Sin embargo, la dificultad para investigar y visibilizar este fenómeno crece en la medida que sólo nos centramos en el control migratorio, el racismo, o COVID-19 como fenómenos separados, esto debido a que el COVID-19 es más 'popular' entre el público y no las historias de migrantes o de personas racializadas. Las historias de muertes masivas por COVID-19 han sido centrales en los medios de comunicación y ha dejado a las y los migrantes sufriendo en las fronteras (Garrett, 2020). Los noticieros en tiempos de las caravanas centroamericanas se enfocaban más en temas de migración, pero ahora el enfoque es en las estadísticas de casos positivos de COVID-19. 


\section{Los Linchamientos Visibilizados}

Cuando miramos más de cerca un desastre migratorio y la fuente de su violencia, se puede observar la ideología de la supremacía blanca y cómo el privilegio histórico de la gente blanca les ha favorecido en el desarrollo de la sociedad, mientras que al mismo tiempo ha posicionado, o empujado, a las comunidades negras y latinoamericanas a condiciones de vulnerabilidad. En los tiempos de esclavitud y durante la emancipación de los esclavizados, los linchamientos en los Estados Unidos eran espectáculos 'necropolíticos' con audiencias masivas como en el teatro. La gente blanca paseaba con la familia para ver el linchamiento de padres, madres e hijos negros en plazas publicas. La comunidad blanca acostumbraba a llevarse recuerdos de los cuerpos linchados y partes mutiladas a sus casas. Hoy en día, los 'linchamientos' siguen ocurriendo en las redes sociales, que han ayudado a convertir la violencia de Estado contra la comunidad negra en un espectáculo viral, con videos que ayudan a revivir asesinatos, palizas, y violencia de todo tipo de manera repetitiva. En este sentido, la injusticia racial ha seguido existiendo en todas las instituciones y prácticas, perpetuando el impacto desproporcionado que afecta a la comunidad negra. Esto significa, por ejemplo, que no sólo la comunidad negra es asesinada desproporcionadamente por la violencia policial en los Estados Unidos, sino que también vemos a las comunidades negras desproporcionadamente afectadas por COVID-19 en contextos globales. Cuando el mensaje de la campaña es 'Las Vidas Negras Importan', implícitamente se dice que todas las vidas importan también, y eso se entiende en la base fundamental de la lucha del movimiento negro.

EI 'linchamiento' de George Floyd ocurrió durante la pandemia del COVID-19 en Estados Unidos. Protestas y manifestaciones en plataformas internacionales siguen reclamando justicia y que se reconozca el racismo y la anti-negritud que permanece no sólo en los departamentos de autoridad policial, sino también en las relaciones interpersonales entre la sociedad. Algunos expertos en salud pública criticaron las demostraciones por no seguir los reglamentos de distanciamiento social. Como contrapunto, se puede afirmar, sin embargo, que el racismo institucional ya estaba presente antes que comenzara la pandemia. Así, los manifestantes en favor de Black Lives Matter parecen estar en su derecho de pedir justicia racial durante la pandemia. La comunidad negra se siente en riesgo de que la policía los asesine, agentes migratorios los deporten y que se contagien de COVID-19 más allá de las manifestaciones. Los Centers for Disease Control and Prevention (CDC, 2020a) -Centros de Control y Prevención de Enfermedades- dan validez a estas preocupaciones debido a que declararon que las minorías étnicas sí tienen un mayor riesgo de morir a causa del virus.

El movimiento Black Lives Matter no está separado del Movimiento por el Derecho a Migrar durante la pandemia del COVID-19 porque ambos apuntan a los factores subyacentes del desastre migratorio. Por ejemplo, hubo una protesta de Black Lives Matter en uno de los cruces fronterizos peatonales de Tijuana para solidarizarse con la denuncia del asesinato de George Floyd en los Estados Unidos y también para denunciar la violencia contra las y los migrantes negros en México. En México existen también fuertes sentimientos de anti-negritud. México participó activamente en la esclavitud histórica de africanos, aunque emanciparon a las personas esclavizadas unos 30 años antes que los Estados Unidos. Más recientemente, se encuentran migrantes haitianos y africanos en tránsito o en asentamientos en México. La externalización de las fronteras ha limitado el acceso de las y los migrantes negros en México sin posibilidad de transitar a los Estados Unidos. Además, las y los migrantes negros son víctimas de violencia en México. Por ejemplo, Maxene Andre, un migrante haitiano, murió en un centro de detención mexicano en Tapachula por falta de atención médica y 11 meses después de su muerte a su familia todavía no le habían devuelto su cuerpo. Así como el asesinato de Floyd en Estados Unidos, en enero de 2020, Junio Camear Jean, un migrante haitiano en Tijuana fue golpeado y asesinado por la policía municipal mexicana mientras suplicaba por su vida y gritaba que tenía asma. Las y los migrantes negros también están afectados por falta de atención médica en los hospitales en tiempos de COVID-19. Estos casos evidencian que Black Lives Matter, el control migratorio y el COVID-19 no son sólo crisis aisladas, sino que también forman parte de un complejo desastre migratorio. Hoy, la visibilidad de este desastre migratorio a través de las redes sociales y de las noticias demuestran el impacto desproporcionado contra la comunidad negra y en migrantes racializados. 


\section{EL TRÁNSITO DURANTE LA PANDEMIA}

Las políticas migratorias en los Estados Unidos trascienden fronteras y apoyan la propagación del virus hacia América Latina. La Política de Medición limita los casos que se evalúan por día y esto causa que atiendan pocas solicitudes de asilo y que se queden las y los migrantes más tiempo en México en condiciones inestables o no aptas para prevenir el contagio de COVID-19 (Slack \& Heyman, 2020). Cada cita para que las y los migrantes se presenten es siempre una posibilidad para que el virus cruce las fronteras de Estados Unidos a México y así, se ponga la vida de las y los migrantes en riesgo. Las y los migrantes tienen que cruzar la frontera, son llevados a custodia, son detenidos mientras son procesados, se presentan frente al juez, y los regresan a México nuevamente (Slack \& Heyman, 2020). Con esto, las y los migrantes y solicitantes de asilo están viviendo en condiciones de riesgo. En su traslado, los y las migrantes son ubicados en albergues con espacio limitado para distanciamiento, y en caso de enfermedad no cuentan con seguros médicos o tienen recursos limitados (Brito, 2020). Todos estos pasos arriesgan más a las y los migrantes que vienen huyendo de la violencia de Estado y se enfrentan a la misma violencia estatal cuando piden asilo en los Estados Unidos. Los solicitantes de asilo que se presentan a sus citas pueden ser detenidos o regresados a México temporalmente o por un periodo extendido. En el caso de que un juez permita una fianza para los solicitantes de asilo, la única oportunidad es salir con libertad condicional bajo la supervisión de Inmigración y Control de Aduanas en Estados Unidos (Slack \& Heyman, 2020).

En estos tiempos de la pandemia se ha visto un aumento en el uso de deportaciones aceleradas. Se encuentran brotes de COVID-19 en los centros de detención de inmigrantes en los Estados Unidos que a veces se encuentran en prisiones privadas. Existen reportes de migrantes que han informado que fueron deportados cuando empezaron a tener síntomas de COVID-19. Los vuelos de repatriados requieren también más atención global porque causan gran preocupación sobre la transmisión del virus. Normalmente, se espera que un vuelo esté lleno de repatriados, a su máxima capacidad, esto produce que los detenidos queden expuestos al coronavirus por la falta de distanciamiento (Slack \& Heyman, 2020). También están documentados vuelos con migrantes que viajaron siendo positivos de COVID-19, al tiempo que el gobierno de los Estados Unidos los trató como los culpables de portar el virus (Garrett, 2020). Estas repatriaciones de migrantes que portan el virus pueden tener consecuencias porque los países de origen suelen tener sistemas de salud precarios, con recursos y servicios escasos. Bajo el actual régimen de control migratorio, existe una baja posibilidad para que las y los migrantes en tránsito puedan seguir las pautas de prevención del COVID-19. Además, la externalización de fronteras 'expande' el tiempo de tránsito cuando se activa la Guardia Nacional y crea barreras simbólicas que migrantes tienen que atravesar. Con esto, las y los migrantes se encuentran tácitamente en periodos de vulnerabilidad social. Es difícil que migrantes o personas en condiciones de refugio tengan los recursos adecuados para cumplir con el autoaislamiento y distanciamiento social (Rodríguez-García-de-Cortázar et al., 2020). Por ejemplo, la falta de recursos limita a las y los migrantes la compra de equipos de protección personal como tapabocas, desinfectantes, e incluso el acceso a agua potable y saneamiento. El brote del coronavirus se considera un desastre global, pero para las y los migrantes la pandemia es también un desastre migratorio que ocurre simultáneamente.

\section{MIGRANTES EN EL PAÍS DE DESTINO}

El caso de los trabajadores esenciales en los Estados Unidos demuestra el impacto del COVID-19 en comunidades de migrantes. Las y los migrantes en Estados Unidos corren un riesgo desproporcionado de contraer COVID-19 porque son los trabajadores esenciales que deben mantener la continuidad de la sociedad. Así, las funciones centrales de la supervivencia social dependen del trabajo de los trabajadores migrantes. Las y los migrantes desempeñan un papel fundamental como proveedores de servicios de alimentos. Por ejemplo, en el sur de California los trabajadores agrícolas se encuentran en primera línea, con la responsabilidad enorme de alimentar al país en tiempos de crisis, sin embargo, no cuentan con la seguridad que cuentan otros trabajadores, ya que muchos son ilegalizados. Con esto, el COVID-19 tiene un impacto desproporcionado en las comunidades de origen latinoamericano. Además, desde agosto de 2020 California está combatiendo incendios forestales severos que también afectan la salud y supervivencia de los trabajadores inmigrantes del sector agrícola.

En la costa este de Estados Unidos, las y los migrantes también se han visto afectados por el COVID-19. En julio del 2020, el gobernador del estado de Delaware reveló un informe que señalaba 
a las y los migrantes que trabajaban en las granjas criadoras de pollos como uno de los grupos con niveles altos de casos positivos de COVID-19, lo que contribuyó a la expansión del contagio en el estado. Por ejemplo, el Washington Post reportó en julio del 2020 que algunos trabajadores migrantes en estas granjas salieron positivos al COVID-19 por la falta de medidas preventivas ofrecidas por sus empleadores. A algunos de esos trabajadores migrantes se les prometió un pago continuo durante su recuperación de COVID-19 pero solo recibieron su pago algunas semanas y pararon de mandárselos.

Algunos trabajadores esenciales migraron de forma irregular y se encontraron en posiciones de vulnerabilidad. Las y los migrantes quedaron excluidos de una gran cantidad de asistencia financiera federal por desastres, como la no elegibilidad para recibir el pago del estímulo que Estados Unidos les dio a los ciudadanos y residentes para aliviar algunas de las circunstancias causadas por la pandemia. La exclusión habla mucho del trato diferencial hacia los migrantes. Por el estatus indocumentado, temor a las autoridades y a los procesos de deportación es probable que no busquen representación legal contra las instituciones que violan sus derechos. Estas decisiones a nivel nacional tienen impactos globales debido a las remesas enviadas desde los Estados Unidos a los países de origen de las y los migrantes para ayudar a sus familias. Los sueldos de las y los migrantes son limitados durante la pandemia por el cierre de sus puestos de trabajo. De manera que la reducción en las remesas puede llegar a afectar ciertas economías en Latinoamérica.

Mientras se alienta a las familias a practicar el distanciamiento social y la cuarentena en el hogar, las y los migrantes no tienen condiciones de trabajo seguras mientras trabajan durante la pandemia para alimentar a países como los Estados Unidos. Las necesidades específicas de los trabajadores migrantes requieren atención y apoyo por políticas que empiecen a reconocer sus contribuciones laborales. Las y los migrantes son categorizados como trabajadores esenciales, pero no reciben beneficios mientras corren peligro de contraer el virus.

Las políticas migratorias y las respuestas al contagio del COVID-19 también funcionan de manera reactiva y no proactiva. En los terrenos fronterizos se han reportado protestas en las que se exige al gobierno mexicano el bloqueo del ingreso de estadounidenses a México. Las luchas limitando la movilidad de turistas de Estados Unidos en un contexto global demuestra la vulnerabilidad del régimen de control migratorio. El Acuerdo de Cooperación entre Guatemala y Estados Unidos resultó en la repatriación de centroamericanos hasta que Guatemala bloqueó a los viajeros de Estados Unidos y terminó la implementación de los reglamentos del Acuerdo (Garrett, 2020). México también tiene restricciones al ingreso de personas al país por razones esenciales, pero no son estrictos en su aplicación para detener viajeros (Slack \& Heyman, 2020). Por ejemplo, el fin de semana del 4 de julio de 2020 en California, cuando se cerraron las playas por el Día de la Independencia de los Estados Unidos para detener COVID-19, se crearon largas líneas de tráfico con automóviles que intentaban llegar a México para divertirse en las playas conocidas como Rosarito y Playas de Tijuana.

\section{INICIATIVAS POR LA SALUD MIGRANTE}

Cuando se toma en consideración la migración transnacional, el tránsito de migrantes y su destino planificado, podría ser beneficioso tratar la experiencia en un contexto de desastre. En lugar de que Estados Unidos responda cerrando fronteras, usando gases lacrimógenos y autorizando la fuerza letal, una respuesta debería ser más bien humanitaria. Las practicas de salud pública como la sana distancia y el lavarse las manos tienen impactos limitados en el control de la pandemia cuando la información no se difunde de manera preventiva y a tiempo (Ferrer Julià, 2020). Una respuesta estratégica al desastre migratorio debería considerar un plan médico para cuidar de la salud de migrantes antes de que se contagien del COVID-19 y planes de mitigación contra el racismo y sentimientos de anti-negritud durante el tránsito. Se requiere implementar acciones apoyando la protección sanitaria y amplificar métodos que reconozcan las consecuencias reales de la desigualdad (Allen et al., 2020).

De manera similar a la respuesta a un desastre relacionado con amenazas naturales, se requiere una planificación para que las iniciativas de prevención y mitigación empiecen a enfocarse en las necesidades de las y los migrantes en tiempos de COVID-19. Las redes basadas en el apoyo social y comunitario pueden mitigar los riesgos para las y los migrantes porque podrían adquirir un sistema de apoyo en caso de que salgan positivos de COVID-19. Cuando un migrante se encuentre deshabilitado mientras se recupera de la enfermedad, una red de apoyo puede ayudar 
de forma financiera con dinero o comida y también puede ser un apoyo emocional y psicológico. La experiencia de un resultado positivo a COVID-19 tiene impactos similares a otras enfermedades terminales. El cáncer, por ejemplo, es una enfermedad que en términos médicos no tiene un cura, sin embargo, se cuenta con diversos mecanismos paliativos y de apoyo psicológico que ayudan a mitigar su impacto. Así, es posible que las preguntas y dudas que pacientes migrantes de coronavirus puedan tener respecto a la enfermedad y su impacto queden sin repuestas concretas, pero las redes comunitarias podrían apoyar la recuperación física y psicológica, además de mitigar sus impactos.

Las y los migrantes en tránsito y en estadía en el país de destino (o en el país de regreso como lo es el caso de México), necesitan la organización de servicios humanitarios. Las organizaciones y los socios comunitarios funcionan según a lo que perciben que son las necesidades de las y los migrantes durante su tránsito por México. La pandemia incluso a puesto limites a los servicios y las prácticas rutinarias de muchas organizaciones civiles. En tiempos de incertidumbre por desastres, las organizaciones se benefician de colaboraciones transnacionales. Las organizaciones civiles pueden depender normalmente de un equipo de voluntariado local e internacional. Durante el inicio de la pandemia, las restricciones de viaje resultaron en recortes de recursos internacionales. El voluntariado cambió a un formato virtual. El apoyo binacional de donaciones de ropa, comida, y de otros elementos de necesidad básica se detuvieron temporalmente y empezaron las sugerencias de seguir las donaciones monetarias. Las ayudas federales y estatales suelen tomar mucho tiempo desde que son realizadas hasta ser recibidas por migrantes, quienes residen en condiciones vulnerables.

Los refugios proporcionan bienes y servicios a las y los migrantes aun cuando cuentan con recursos limitados. Al comienzo de la pandemia en lugares como Tijuana, muchos albergues implementaron cierres en la aceptación de nuevos migrantes para prevenir el contagio. En tiempos de políticas migratorias como los Migrant Protection Protocols, cierres de fronteras, restricciones de riesgo de viajes internacionales y controles de cruce de fronteras, prácticas como el cerrar las puertas de un alberge puede tener efectos catastróficos para migrantes en posiciones de vulnerabilidad. En tiempos de crisis social y durante desastres, los más afectados son personas que viven en condiciones de precariedad. La migración irregular en México no se ha acabado y las y los migrantes indocumentados se resisten a buscar ayudas de instituciones por miedo a ser retornados a sus países de origen. Esta es una situación muy difícil en contexto de la pandemia debido a que los migrantes desconfían de instituciones estatales, pero al mismo tiempo esa desconfianza puede ser fatal para ellos, y la sociedad en general, si es que no recurren a centros formales de salud para reconocer y tratar la enfermedad.

La interacción transfronteriza es importante para prevenir el impacto concurrente del desastre migratorio, que afecta negativamente a migrantes en tránsito. La asistencia internacional no solo aporta recursos, sino que también consigue visibilizar la problemática. Las y los migrantes en transito enfrentaban violaciones de sus derechos por el Estado al limitar su derecho a la movilidad. La atención de aliados en el extranjero ayuda a documentar casos de abuso contra migrantes. Los medios de comunicación visibilizan también las condiciones en las que se encuentran las y los migrantes y atraen, por ejemplo, a organizaciones como las Naciones Unidas que denuncian los abusos contra los derechos de migrantes. La migración forzada, la ley de inmigración, la criminalización y el COVID-19 crean condiciones de vulnerabilidad que afectan a los migrantes, pero al mismo tiempo conducen la movilización de aliados para actuar y responder a las injusticias.

El derecho a migrar de manera segura también incluye el derecho a la migración libre de contagio del COVID-19. Los gobiernos han tratado de detener el movimiento migratorio y han expuesto a migrantes a la violencia y a la muerte, haciendo necesario adoptar practicas humanitarias. Las y los migrantes deben tener la protección de su seguridad mientras transitan por un país como México o cuando llegan a la frontera de Estados Unidos. Migrar en tiempos de COVID-19 mientras Estados Unidos sigue en proceso de externalización de sus fronteras es una sentencia inhumana. No solo están deteniendo a las y los migrantes más tiempo en el tránsito, sino que también los están exponiendo a un virus cuyos efectos son aún desconocidos. A mediados de 2020, mientras los gobiernos empezaron a abrir sus economías al exterior, las puertas de los cruces fronterizos permanecían cerradas para migrantes que deseaban transitar por México, y en octubre del 2020, una caravana centroamericana fue detenida en la frontera sur de México. 
El COVID-19 ha afectado la economía de países que ya se encontraban desestabilizados antes de la pandemia, agravando más aún la falta de oportunidades en los países de origen de los migrantes. Así, la migración forzada puso a migrantes en peligro de contagio del COVID-19 y, sin embargo, las caravanas siguen ofreciendo esperanza en tiempos de desastre y de fronteras cerradas. Por su parte, la militarización y securitización de la frontera sur de México cerró las puertas a migrantes durante la pandemia y desafortunadamente no dio acceso para el tránsito a la caravana de migrantes vulnerabilizados. En tiempos de pandemia, países de tránsito como México deberían adoptar perspectivas de humanización para detener el virus y apoyar la movilidad segura de los migrantes.

\section{CONCLUSIONES}

El régimen de control migratorio funciona bajo la intersección de un desastre migratorio con impactos sociales que ocurren de manera concurrente. Las prácticas anti-migratorias durante la pandemia no solo son problemas de gobiernos, sino que también reflejan los resultados de siglos de racismo y de desigualdades en la salud pública. El gobierno de los Estados Unidos intenta implementar un sistema no solo anti-migrante sino también contra la movilidad humana. Los números de casos en los Estados Unidos demuestran las fallas en la administración de Trump. Hasta el 14 de agosto de 2020, se documentaron en los Estados Unidos 5.228.817 casos positivos de COVID-19 y la administración de Trump es indirectamente culpable del fallecimiento de al menos 166.317 personas (CDC, 2020b). La política migratoria en el momento es de detener el contagio del virus para que no siga cruzando fronteras y afectando la salud global. Las y los migrantes en tránsito por México están enfrentando múltiples amenazas y desafortunadamente están siendo criminalizados, rastreados y culpados por fenómenos sociales fuera de su control, lo que constituye un desastre.

En la gestión de desastres una meta es implementar un plan de mitigación para reducir el riesgo de comunidades en condiciones de vulnerabilidad. Los planes de mitigación intentan frenar el ciclo de desastres y desarrollan estrategias para reducir los riesgos, impactos, y pérdidas de vida (FEMA, 2020). Un plan de mitigación en un 'desastre migratorio' debe abordar los factores subyacentes del régimen de control migratorio para prevenir que sean victimizados y minimizar los 'linchamientos' de migrantes en el tránsito. También, las repatriaciones tienen que ser reconsideradas y los centros de detención migratoria evacuados (Brito, 2020; Rodríguez-Garcíade-Cortázar et al., 2020). Por otro lado, el control del COVID-19 requiere políticas públicas basadas en enfoques humanitarios que integren a las y los migrantes y otros grupos marginalizados en procesos de colaboración donde puedan adaptar sus capacidades en respuestas comunitarias. Aunque un 'régimen de terror' atenta para gobernar, detener y poner alto a la migración interna y transnacional, los movimientos sociales revelan la ingobernabilidad y la autonomía de la movilidad humana que convierte a Latinoamérica en campo de conflicto y sitio de lucha (Cordero et al., 2019). Muchas organizaciones civiles y acciones de voluntariado no pueden proporcionar recursos a nivel binacional como lo hacian antes de la pandemia. Sin embargo, este momento de crisis exige creatividad para mantener los esfuerzos que salvan vidas de las y los migrantes en tránsito. Asimismo, en la academia se necesita adoptar un modelo de colaboración entre investigadores, grupos comunitarios, y migrantes para planificar juntos métodos de investigación-acción que replanteen el régimen de control de fronteras y para mitigar los impactos concurrentes del racismo y COVID-19 en un desastre migratorio.

Las perspectivas de los estudios sobre desastres demuestran que el régimen de control migratorio refleja la complejidad de las relaciones sociales. Durante la pandemia del COVID-19, países alrededor del mundo como Canadá, Italia, China, y Estados Unidos detuvieron prácticas de la vida cotidiana con el cierre de lugares públicos y requisitos de cuarentena forzada. Por primera vez, una gran parte de la población privilegiada experimentó aislamiento y exclusión temporaria. Los sentimientos de ansiedad y los deseos de querer volver a la normalidad no se comparan con las experiencias que viven las y los migrantes bajo sistemas de control social en su vida diaria. La pandemia está abriendo oportunidades para reflexionar sobre el antirracismo, y las relaciones sociales para empezar a desmantelar el régimen de control migratorio. 


\section{REFERENCIAS}

Acuña, R. (2015). Occupied America: A history of Chicanos. Longman.

Alarcón Acosta, R., \& Ortiz Esquivel, C. (2017). Los haitianos solicitantes de asilo a Estados Unidos en su paso por Tijuana. Frontera Norte, 29(58), 171-179.

Allen, A., Sarmiento, J.P., \& Sandoval, V. (2020). Los estudios Latinoamericanos de reducción del riesgo de desastres en el contexto de la pandemia del COVID-19. Revista de Estudios Latinoamericanos sobre Reducción del Riesgo de Desastres REDER, 4(2), 1-6. http://revistareder.com/ handle-0719-8477-2020-066

Allen, A., Belkow, T., Escalante Estrada, C., de los Ríos, S., Kamiya, M., Miranda, L., Wesely, J. \& Zilbert Soto, L. (2017). De la mitigación de desastres a la interrupción de trampas de riesgo: La experiencia de aprendizaje-acción de cLIMA sin Riesgo. Revista de Estudios Latinoamericanos sobre Reducción del Riesgo de Desastres REDER, 1(1), 6-28. http://www.revistareder.com/ojs/index.php/reder/article/ view $/ 2$

Armenta, A. (2017). Protect, serve, and deport: The rise of policing as immigration enforcement. University of California Press.

Bankoff, G. (2006, junio 11). The tale of the three pigs: Taking another look at vulnerability in the light of the Indian Ocean Tsunami and Hurricane Katrina. SSRC. https://items.ssrc.org/understandingkatrina/the-tale-of-the-three-pigs-taking-another-look-at-vulnerability-in-the-light-of-the-indianocean-tsunami-and-hurricane-katrina/

Brito, M.O. (2020). Covid-19 in the Americas: Who's looking after refugees and migrants?. Annals of Global Health, 86(1), 69.

Centers for Disease Control and Prevention CDC. (2020a, julio 24). Health equity considerations and racial and ethnic minority groups. National Center for Immunization and Respiratory Diseases, Division of Viral Diseases. https://www.cdc.gov/coronavirus/2019-ncov/community/health-equity/ race-ethnicity.html

Centers for Disease Control and Prevention CDC. (2020b, Agosto 14). Cases in the United States. National Center for Immunization and Respiratory Diseases, Division of Viral Diseases. https:// www.cdc.gov/coronavirus/2019-ncov/cases-updates/cases-in-us.html

Chishti, M., Pierce, S., \& Bolter, J. (2017, enero 26). The Obama record on deportations: Deporter in chief or not?. Migration Policy Institute. https://www.migrationpolicy.org/article/ obama-record-deportations-deporter-chief-or-not

Cordero, B., Mezzadra, S., \& Varela Huerta, A. (2019). América latina en movimiento: Migraciones, límites a la movilidad y sus desbordamientos. Traficantes de Sueños.

Cruz, A. R. (2017). Antropología de emergencia en el trabajo con menores y mujeres centroamericanas en busca de asilo. Revista Internacional de Filosofía, 19, 207-217.

De Genova, N., \& Roy, A. (2020). Practices of illegalization. Antipode, 52(2), 352-364. https://doi. org/10.1111/anti.12602

Díaz-Barriga, M., \& Dorsey, M.E. (2020). Fencing in democracy: Necrocitizenship and the US-Mexico border wall. Duke University Press.

Dubuisson, P. U. (2018). Sobrevivientes: Ciudadanos del mundo (Ser. Círculo de lecturas). ILCSA Ediciones.

Oviedo, D., Elfers, A., Kurimoto, K., Irwin, R. M. K., \& Silva Hernández Aída. (2020). Caravaneros. Festina Publicaciones.

Farías, C. (2020). La comunicación de la emergencia en erupciones volcánicas en Chile y su impacto durante la pandemia del COVID-19. Revista de Estudios Latinoamericanos sobre Reducción del Riesgo de Desastres REDER, 4(2), 123-124. http://www.revistareder.com/ojs/index.php/reder/article/ view/55

Federal Emergency Management Agency FEMA. (2020, julio 24). Hazard mitigation planning. FEMA. https://www.fema.gov/emergency-managers/risk/hazard-mitigation-planning

Ferrer Julià, M. (2020). La prevención, fase cero en la gestión del riesgo: ¿Se podría haber evitado parte de los daños del COVID19 con prevención? Revista de Estudios Latinoamericanos sobre Reducción del Riesgo de Desastres REDER, 4(2), 125. http://www.revistareder.com/ojs/index.php/reder/article/ view/56 
Fitzgerald, D.S. \& Cook-Martín, D. (2015). Elegir a la población: Leyes de inmigración y racismo en el continente americano. En P. Yankelevich (Ed.), Inmigración y racismo: Contribuciones a la historia de los extranjeros en México (pp. 29-58). El Colegio de México, Centro de Estudios Históricos.

Friedman, J., Calderón-Villarreal Alhelí, Bojorquez, I., Hernández Carlos Vera, Schriger, D. L., \& Hirashima, E. T. (2020). Excess out-of-hospital mortality and declining oxygen saturation: The sentinel role of ems data in the covid-19 crisis in Tijuana, Mexico. Annals of Emergency Medicine, 76(4), 413-426. https://doi.org/10.1016/j.annemergmed.2020.07.035

García, M.C. (2006). Seeking refuge: Central American migration to Mexico, the United States, and Canada. University of California Press.

Garrett, T.M. (2020). Covid-19, wall building, and the effects on migrant protection protocols by the Trump administration: The spectacle of the worsening human rights disaster on the Mexico-U.S. border. Administrative Theory \& Praxis, 42 (2), 240-248.

Hartman, C.W., \& Squires, G.D. (2006). There is no such thing as a natural disaster: Race, class, and hurricane Katrina. Routledge.

Hennessy-Fiske, M. (2019, mayo 24). Six migrant children have died in U.S. custody. Here's what we know about them. Los Angeles Times. https://www.latimes.com/nation/la-na-migrant-child-borderdeaths-20190524-story.html

Henricks, K. (2015). Bursting whose bubble? The racial nexus between social disaster, housing wealth, and public policy. Social Justice Research, 28(3), 318-338.

Jacobs, F. (2019). Black feminism and radical planning: New directions for disaster planning research. Planning Theory, 18(1), 24-39.

Klinenberg, E. (2015). Heat wave: A social autopsy of disaster in Chicago (2da Ed.). University of Chicago Press.

Lytle Hernandez, K. (2015). ¡La migra!: Una historia de la patrulla fronteriza de Estados Unidos. Fondo de Cultura Económica.

Mbembe, A. (2019). Necropolitics. Duke University Press.

Mezzadra, S. (2005). Derecho de fuga: Migraciones, ciudadanía y globalización (Mapas, 11). Traficantes de Sueños.

Miller, J., \& Wang, X. (2018). When there are no therapists: A psychoeducational group for people who have experienced social disasters. Smith College Studies in Social Work, 88(1), 39-58.

Navarrete, F. (2018). México racista: Una denuncia. Grijalbo.

París Pombo, M.D. (2017). Violencias y migraciones centroamericanas en México. El Colegio de la Frontera Norte.

París Pombo, M.D., \& Montes, V. (2020). Visibilidad como estrategia de movilidad: El éxodo centroamericano en México (2018-2019). Entrediversidades, 7(1), 9-38.

Rios-Contreras, N. (2020). Forced displacement of migrants from countries of origin and their transit migration through Mexico to the US. En H. Kara and S-M Khoo. (Eds.), Researching in the Age of COVID-19 Volume III: Creativity and Ethics (pp. 70-79). Policy Press.

Rodríguez-García-de-Cortázar, A., Leralta-Piñán, O., Jiménez-Pernett, J., \& Ruiz-Azarola, A. (2020). Covid-19 en migrantes y minorías étnicas. Gaceta Sanitaria. https://doi.org/10.1016/j. gaceta.2020.06.002

Sandoval-García, C. (2017). Exclusion and forced migration in Central America: No more walls. Palgrave Macmillan.

Silva Hernández, A., y Padilla Orozco, V. (2020). Instituciones en crisis y acción colectiva frente a las migraciones globales. el caso de la llegada de haitianos a Tijuana, B.C., 2016-2017. Desafíos, 32(1), 77-113.

Slack, J., \& Heyman, J. (2020). Asylum and mass detention at the U.S.-Mexico border during covid-19. Journal of Latin American Geography, 19(3), 334-339.

Swanson, K., \& Torres, R. M. (2019). Migración de niños y violencia transnacional en Centroamérica y Norteamérica. Revista Del Cisen Tramas/Maepova, 7(2), 281-309.

Tierney, K. (2019). Disasters: A Sociological Approach. Polity Press. 
Thomas, D. S. K., Phillips, B. D., Lovekamp, W. E., \& Fothergill, A. (2013). Social vulnerability to disasters, second edition (2nd ed.). CRC Press.

Varela Huerta, I.A. (2020). Apuntes para un feminismo antirracista después de las caravanas de migrantes. En V. Gago, M. Malo, L. Cavallero, H. Silvestre, A. Varela Huerta, A. Carrillo Vidal, J. Manzi Araneda, K. Hidalgo Cordero, A. Santillana Ortiz, y B. Valencia Castro, La internacional feminista: luchas en los territorios y contra el neoliberalismo. Traficantes de Sueños.

Varela Huerta, I.A. (2019). Nunca más un México sin nosotras: Feminismo y mujeres afromexicanas. Política y Cultura, 51, 105-124.

Villafuerte Solís, D. (2020). Introducción. En D. Villafuerte Solís y M. E. Anguiano Téllez. (Eds.), Movilidad humana en tránsito: Retos de la Cuarta transformación en política migratoria (pp. 11-26). Consejo Latinoamericano de Ciencias Sociales. 